chemisch gebundenen Wassers in dem Salze würde 2,22 Procent davon verlangen.

\title{
Ueber Jodreactionen;
}

\author{
von \\ Dr. A. Overbeck.
}

Chatin und Gaultier de Claubry haben kürzlich *) Versuche angestellt uber die Genauigkeit der verschiedenen Verfahrungsarten zur Erkennung und Abscheidung des Jods. Der Palladiumlösung, dem Schwefelkohlenstoff und Chloroform räumen sie nur eine untergeordnete Bedeutung ein, und geben im Allgemeinen der schon 1814 vorgeschlagenen Methode der Abscheidung des Jods als Jodamylum den Vorzug, und zwar ernpfehlen sie, statt des Chlors oder der Schwefelsäure als das vorzüglichste Mittel zur Abscheidung des Jods die Salpetersäure oder ein Gemisch von Salpetersäure und Schwefelsäure.

Vergleichende Versuche haben mich gelehrt, dass folgendes Verfahren noch vorzüglicher ist.

Man übergiesst in einem Probircylinder etwas Stärke oder Zucker mit concentrirter Salpetersäure und erwämt iiber der Spirituslampe so lange gelinde, bis eine lebhafte Gasentwickelung eintritt. Sodann entfernt man die Spirituslampe und leitet das nunmehr entwickelte Gas (die Entwickelung desselben dauert nun ohne weilere Erwärmung stetig fort) in die mit Stärkekleister versetzte zu prüfende Flüssigkeit. Enthält dieselbe nur ein Milliontel Jodkalium, so entsteht sofort Bläuung, bei weiterem Einleiten scheidet sich das Jodamylum flockig aus und setzt sich in der Rube als compacter fassbarer Niederschlag $\mathrm{ab}^{* *}$ ).

Eine solche Genauigkeit gewähren die übrigen Prüfungsmethoden nicht. Zugleich dürfte dieses Verfahren auch noch deshalb vorzüglicher sein, weil die Gefahr der Verunreinigung mit Chlorjod ${ }^{* *}$ ) hierbei ferner liegt, als bei dem friber von Chatin angewandten Verfahren

*) Journ. de Pharmacie et de Chimie. Septembre 1852. p. 194.

* ) Auf diese Weise habe ich Jod aufgefunden in mehreren Pflanzenaschen, namentlich in der Asche mehrerer Ranunculaceen, Ranunculus fammula, Ficaria ranunculoides etc.

* Böttcher machte nätnlich in der diesjährigen Versammlung der Naturforscher und Aerzte in Wiesbaden darauf aufmerksam, dass alle(?) starke Salpetersäure Jod als Chlorjod enthalte und deshalb Chatin's Versuche nicht verlïsslich erscheinen möchten. 